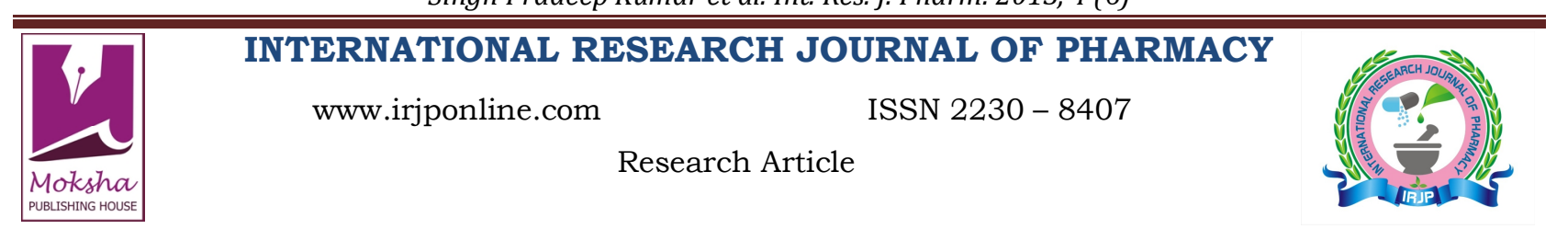

\title{
DEVELOPMENT AND VALIDATION OF A STABILITY INDICATING RP-HPLC METHOD FOR DETERMINATION OF ELETRIPTAN IN ELETRIPTAN HYDROBROMIDE ORALLY DISINTEGRATING TABLETS \\ Singh Pradeep Kumar*, Subas Chandra Dinda \\ School of Pharmaceutical Education \& Research, Berhampur University, Bhanja Bihar, Berhampur (Gm.)-Odisha, India \\ *Corresponding Author Email: pksmpharm1978@gmail.com
}

Article Received on: 10/03/13 Revised on: 01/04/13 Approved for publication: 11/05/13

DOI: $10.7897 / 2230-8407.04640$

IRJP is an official publication of Moksha Publishing House. Website: www.mokshaph.com

(C) All rights reserved.

\section{ABSTRACT}

A simple, precise, rapid and accurate stability indicating reverse phase high performance liquid chromatography has been developed and validated for the estimation of Eletriptan Hydrobromide in tablet dosage form. Separation was carried on a Waters e 2695 HPLC system separation module with Empower 2 software, PDA detector waters 2998 and Thermo- $C_{18}$ analytical column $(5 \mu \mathrm{m} ; 150 \times 4.6 \mathrm{~mm})$, was operated in isocratic mode using mobile phase consisting of (methanol and water in the ratio of 35:65) is used in the ratio of 35:65 and at a flow rate of $1 \mathrm{ml} / \mathrm{min}$ with detection wavelength of $227 \mathrm{~nm}$ by an injection volume of $20 \mu \mathrm{l}$ and entire separation was carried out at $35^{\circ} \mathrm{C}$ column temperature. The linearity was found in the range of $5.0-500.0 \mu \mathrm{g} / \mathrm{ml}$ and showed a correlation co-efficient of 0.9999 . The retention time of Eletriptan Hydrobromide was found to be 7.0. This study concluded that the proposed method was found to be accurate, reproducible and consistent which is useful for the routine determination of Eletriptan in tablet dosage form. The method is validated as per ICH guidelines by determining its specificity, accuracy, precision, linearity \& range, ruggedness, robustness and system suitability.

KEY WORDS: Eletriptan Hydrobromide, RP-HPLC, Method Development, Validation.

\section{INTRODUCTION}

Eletriptan is a selective 5-hydroxytryptamine 1B/1D (5$\mathrm{HT} 1 \mathrm{~B} / 1 \mathrm{D})$ receptor antagonist used mainly to treat migraine headache. Eletriptan binds with high affinity to $5-\mathrm{HT}_{1 \mathrm{~B}}, 5-$ $\mathrm{HT}_{1 \mathrm{D}}$ and $5-\mathrm{HT}_{1 \mathrm{~F}}$ receptors. Eletriptan has no significant pharmacological activity on adrenergic alpha $a_{1}$, alpha 2 or beta; dopaminergic $\mathrm{D}_{1}$ or $\mathrm{D}_{2}$; muscarinic; or opioid receptors. The activation of 5-HT $\mathrm{H}_{1}$ receptors located on intracranial blood vessels, including those on the arteriovenus anastomoses, leads to vasoconstriction, which is correlated with the relief of migraine headache. Eletriptan and its conventional dosage forms are not official in any of the official compendia. Chemically ${ }^{1}$, it is (R) -3-[(1-Methyl-2-pyrolidinyl)methyl]-5[2-(phenylsulphonyl)ethyl]-1H-indole monohydrobromide (m.f. $\mathrm{C}_{22} \mathrm{H}_{26} \mathrm{~N}_{2} \mathrm{O}_{2} \mathrm{~S} . \mathrm{HBr}$; m.w. 463.40) [1] [2] Figure 1. Literature survey revealed spectrophotometric methods and HPLC methods in conventional dosage form for estimation of Eletriptan ${ }^{2-7}$. An attempt has been made to develop a new stability indicating robust and cost effective RP-HPLC method for its estimation in orally disintegrating tablet dosage form with good accuracy and precision ${ }^{8-11}$. The method was validated according to the ICH guidelines ${ }^{12}$.

\section{MATERIAL AND METHODS}

Eletriptan Hydrobromide was obtained from SMS Pharma, Hyderabad. Methanol used was of HPLC grade from E. Merck, India. HPLC grade water was obtained using millipore water purification system. All volumetric-glassware were pre-calibrated by the manufacturer (Borosil) and were of grade A. Tablets manufactured in the laboratories Ltd; used for estimation.

\section{Method Development \\ Preparation of Standard and Sample Solutions \\ Procedure for Calibration Curve of Eletriptan Hydrobromide \\ Accurately weighed quantity of $20.23 \mathrm{mg}$ of Eletriptan Hydrobromide was dissolved in $100 \mathrm{ml}$ volumetric flask with}

the diluent. From this stock solution, concentrations of 5, 10, 25, 50, 100 and $150 \mu \mathrm{g} / \mathrm{ml}$ of Eletriptan Hydrobromide and constructed the calibration curve at a detection wavelength of $227 \mathrm{~nm}$ which was used for estimation (Figure $2 \&$ Figure $3 \mathrm{a}$ ).

\section{Assay Procedure for Sample Solution preparation:}

Accurately weighed quantity of equivalent powder of $20 \mathrm{mg}$ of Eletriptan from 20 tablets was dissolved in diluent in $250 \mathrm{ml}$ volumetric flask and $50 \mathrm{ml}$ of methanol was added; after 15 minutes of sonication with intermittent shaking further diluted with methanol to fall in working range concentration for the estimation by using the calibration curve (Figure 3b).

\section{Method Validation}

The proposed method was validated according to ICH guidelines in terms of parameters like Specificity, Accuracy, Precision, Linearity, LOD and LOQ.

\section{System Suitability Parameters}

For system suitability six replicates of standard solutions of Eletriptan Hydrobromide was injected into the system and studied the suitability parameters like Plate number $(\mathrm{N})$, Tailing factor $(\mathrm{T})$ and Percentage relative standard deviation (\%RSD) were studied with the help of standard chromatograms (Table 1)

\section{Linearity and Range}

The linearity of calibration curve (analyte to peak area ration Vs concentration) in pure solution was checked over the concentration ranges of $5.0-150.0 \mu \mathrm{g} / \mathrm{ml}$ for Eletriptan Hydrobromide. The linearity was evaluated by linear regression analysis, using least square method. The calibration curve was linear in the studied range and equations of the regression analysis obtained for Eletriptan Hydrobromide Y: $17641 \mathrm{X}+22685$. Correlation co-efficient values for Eletriptan Hydrobromide found to be 0.9993 (Table 2). 


\section{Accuracy}

To study reliability, suitability and accuracy of the method, recovery studies were carried out, by adding a known quantity of standard to the placebo. The recovery study was carried out as $50 \%, 80 \%, 100 \%, 120 \% \& 150 \%$ level and the contents were determined from respective chromatogram. From the results obtained we conclude that method was accurate (Table 3).

\section{Precision}

The precision of the test method was done by performing assay on six replicate determination of sample preparation at test concentration level (as per method of analysis) and calculated relative standard deviation of assay results. Six replicates of from standard solutions were injected and peak areas were obtained and \% RSD was calculated (Table 4).

\section{Limit of Detection}

Limit of detection is the lowest amount of an analyte that can be detected by injecting decreasing amount, not necessarily quantity by the method, under the stated experimental conditions. The minimum concentration at which the analyte can be detected was determined from the linearity curve by applying the formula (Table 1).

\section{$\mathrm{LOD}=3.3 \mathrm{SD} / \mathrm{Slope}$}

\section{Limit of Quantitation}

Limit of quantitation is the lowest amount of an analyte that can be estimated quantitatively by injecting decreasing amount of the drug with acceptable precision and accuracy under the stated experimental conditions of the method. The minimum concentration at which the analyte can be detected was determined from the linearity curve by applying the formula (Table 1). The limit of quantitation can be obtained from linearity curve by applying the following formula (Table 1).

$$
\mathrm{LOQ}=10 \mathrm{SD} / \text { Slope }
$$

Table 1: System suitability Parameters

\begin{tabular}{|c|c|}
\hline System Suitability Parameters & Eletriptan Hydrobromide \\
\hline Linearity range & $5-150 \mu \mathrm{g} / \mathrm{ml}$ \\
\hline Tailing Factor & 1.5 \\
\hline Number of theoretical Plates & 8775 \\
\hline Retention Time & About 7.0 \\
\hline LOQ & $0.25 \mu \mathrm{g}$ \\
\hline LOD & $0.08 \mu \mathrm{g}$ \\
\hline
\end{tabular}

Table 2: Linearity Data for Eletriptan Hydrobromide

\begin{tabular}{|c|c|}
\hline $\begin{array}{c}\text { Concentration of Eletriptan } \\
\text { Hydrobromide }(\boldsymbol{\mu g} / \mathbf{m l})\end{array}$ & $\begin{array}{c}\text { Peak Area of Eletriptan } \\
\text { Hydrobromide }\end{array}$ \\
\hline 5 & 91205 \\
\hline 10 & 182411 \\
\hline 25 & 456029 \\
\hline 50 & 912058 \\
\hline 100 & 1824117 \\
\hline 150 & 2736176 \\
\hline
\end{tabular}

Table 3: Recovery studies of Eletriptan Tablets

\begin{tabular}{|c|c|c|c|c|}
\hline Sample No. & $\begin{array}{c}\text { Amount added } \\
(\mathrm{mg})\end{array}$ & $\begin{array}{l}\text { Amount recovered } \\
(\mathrm{mg})\end{array}$ & \% Recovery & Mean \% Recovery \\
\hline Accuracy $50 \%-1$ & 10.19 & 10.12 & 99.31 & \multirow[t]{3}{*}{100.39} \\
\hline Accuracy $50 \%-2$ & 10.17 & 10.20 & 100.29 & \\
\hline Accuracy $50 \%-3$ & 10.13 & 10.29 & 101.58 & \\
\hline Accuracy $80 \%-1$ & 16.09 & 16.13 & 100.25 & \multirow[t]{3}{*}{101.06} \\
\hline Accuracy $80 \%-2$ & 16.36 & 16.89 & 103.24 & \\
\hline Accuracy $80 \%-3$ & 16.26 & 16.21 & 99.69 & \\
\hline Accuracy $100 \%-1$ & 20.10 & 19.98 & 99.40 & \multirow[t]{3}{*}{99.83} \\
\hline Accuracy $100 \%-2$ & 20.62 & 20.76 & 100.68 & \\
\hline Accuracy $100 \%-3$ & 20.48 & 20.36 & 99.41 & \\
\hline Accuracy $120 \%-1$ & 24.18 & 24.15 & 99.88 & \multirow[t]{3}{*}{99.84} \\
\hline Accuracy $120 \%-2$ & 24.90 & 24.85 & 99.80 & \\
\hline Accuracy $120 \%-3$ & 24.34 & 24.30 & 99.84 & \\
\hline Accuracy $150 \%-1$ & 32.62 & 32.76 & 100.43 & \multirow[t]{3}{*}{100.00} \\
\hline Accuracy $150 \%-2$ & 32.44 & 32.28 & 99.51 & \\
\hline Accuracy $150 \%-3$ & 32.42 & 32.44 & 100.06 & \\
\hline Overall Mean & \multicolumn{4}{|c|}{100.22} \\
\hline SD & \multicolumn{4}{|c|}{0.52} \\
\hline$\%$ RSD & \multicolumn{4}{|c|}{0.52} \\
\hline
\end{tabular}

Table 4: Precision of developed method at working level

\begin{tabular}{|c|c|}
\hline Sample no. & Peak Area (AU) \\
\hline 1 & 729647 \\
\hline 2 & 718952 \\
\hline 3 & 718452 \\
\hline 4 & 727422 \\
\hline 5 & 728488 \\
\hline 6 & 718595 \\
\hline Mean & 723592.67 \\
\hline SD & 5444.67 \\
\hline RSD & 0.75 \\
\hline
\end{tabular}

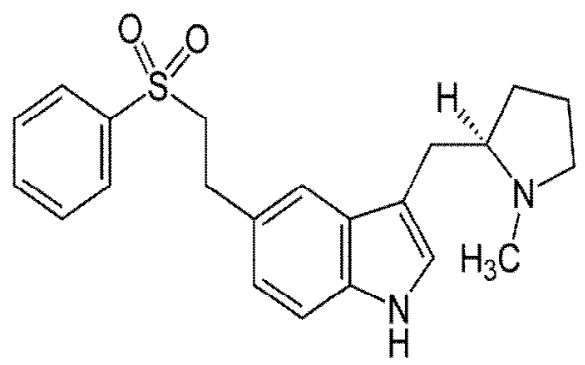

Figure-1: Chemical structure of Eletriptan Hydrobromide 


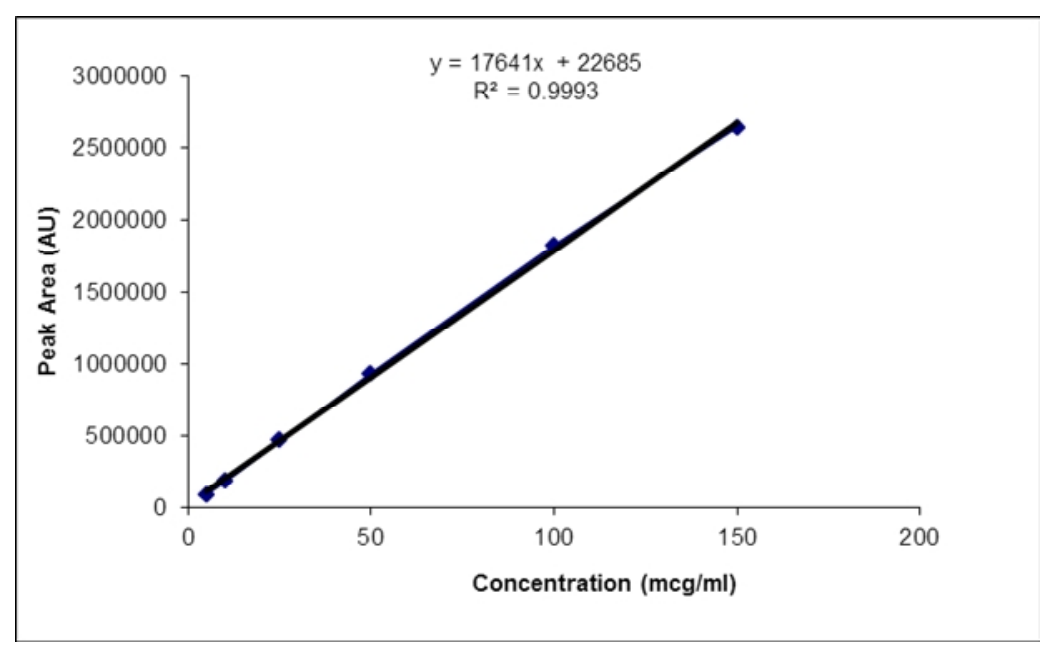

Figure 2-Linearity graph of Eletriptan Hydrobromide

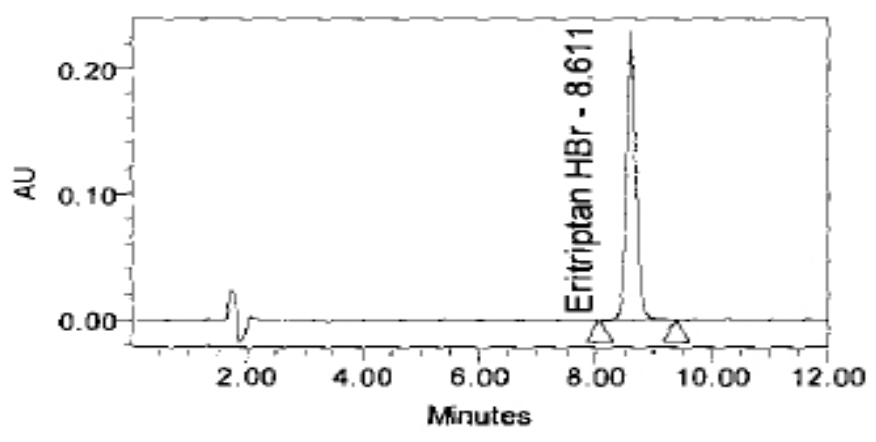

Figure 3a HPLC Chromatogram of Standard Eletriptan Hydrobromide

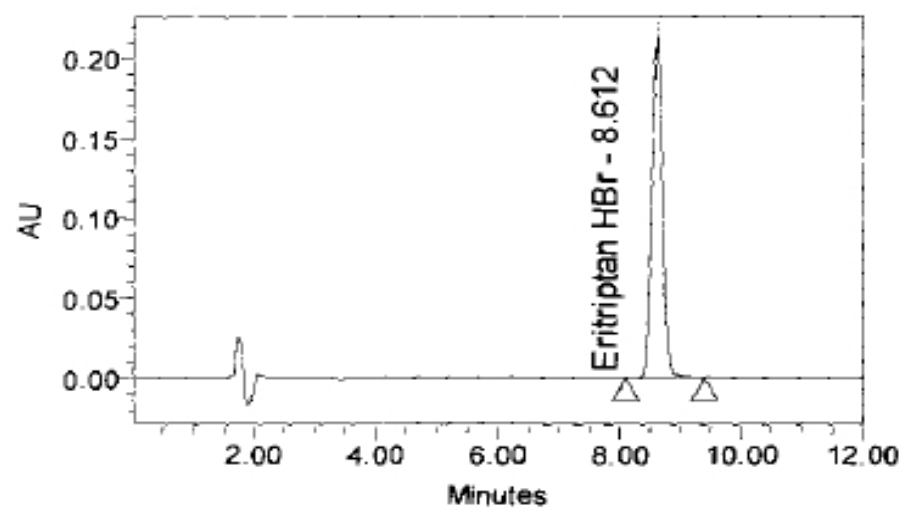

Figure 3b HPLC Chromatogram of Eletriptan Sample

\section{RESULTS AND DISCUSSION}

The separation was carried on Waters 2695 Isocratic HPLC system separation module with EMPOWER 2 software, PDA detector waters 2998 and Symmetry- $\mathrm{C}_{18}$ analytical column $(5 \mu \mathrm{m} ; 250 \times 4.6 \mathrm{~mm})$, was operated in isocratic mode using mobile phase consisting of methanol and water in the ratio of $35: 65$ is used at a flow rate of $1.0 \mathrm{ml} / \mathrm{min}$ with detection wavelength of $227 \mathrm{~nm}$, by an injection volume of $20 \mu \mathrm{l}$ and entire separation was carried out at temperature $35^{\circ} \mathrm{C}$ for column. Under the described experimental conditions, sharp peaks that belong to Eletriptan Hydrobromide were obtained at retention time about $8.0 \mathrm{~min}$. System suitability studies were carried out and Plate number $(\mathrm{N})$, Tailing factor $(\mathrm{T})$ and Percentage relative standard deviation (\%RSD) were found and are presented (Table) 1. The Linearity (Table 2) was obtained in the concentration range 5 to $150 \mu \mathrm{g} / \mathrm{ml}$ for Eletriptan Hydrobromide with correlation coefficient of 0.9993. The accuracy of the method was determined by performing recovery studies at $50 \%, 80 \%, 100 \%, 120 \%$ \& $150 \%$ were found within the limits (Table 3 ). The precision of the method was also found to be good (Table 4). The limit of detection (LOD) and Limit of Quantitation (LOQ) of the developed method were determined by injecting progressively low concentrations of the standard solutions using the developed RP-HPLC method (Table 1). 


\section{CONCLUSION}

The HPLC method developed is accurate, precise, reproducible and specific. The method is linear over a wide range, economical and utilizes a mobile phase which can be easily prepared. All these factors make this method suitable for quantification of Eletriptan in tablets. The method developed was then subjected to validation as per ICH guidelines and showed that method is linear, precise, accurate and robust.

\section{ACKNOWLEDGEMENT}

The authors are thankful to $\mathrm{M} / \mathrm{s}$ Panacea Biotec Limited for the support provided during research work.

\section{REFERENCES}

1. The United States Food and Drug Administration, US Department of Health and Human Services; Prescribing Information 2002:12.

2. Subas Chandra Dinda et al (2013). Development and validation of RPHPLC method for quantitative analysis of Amlodipine besylate in pure and Pharmaceutical Formulations. Research Journal of Pharmacy. 6(2), 204-207.

3. Zecevic Mira et al. (2009). Study of forced degradation behavior of Eletriptan Hydrobromide by LC and LC-MS and development of stability-indicating method, Journal of Pharmaceutical and Biomedical Analysis. 50, 622-629.

4. Zecevic Mira et al. (2006). Validation of an HPLC method for the simultaneous determination of Eletriptan and UK 120.413, Journal of Serbian Chemical Society. 71(11), 1195-1205.

5. Rao A Lakshamana et al.(2010). RP-HPLC Method for the estimation of Eletriptan in Pharmaceutical Dosage Forms, International Journal of Chemical, Enviromental and Pharmaceutical Research. 1(2), 95-99.
6. Swamy G Kumar et al.(2011) Spectrophotometric Method for the estimation of Eletriptan Hydrobromide in Pure and Tablet Dosage Forms, International Journal of Chemical and Analytical Science. 2(8), 123-125.

7. Rajasekhar L., et al.(2011). Development and Validation of Derivative Spectrophotometric Method for Quantitative Estimation of Eletriptan Hydrobromide in Bulk and Pharmaceutical Dosage Forms, International Journal of Research in Pharmaceutical and Biomedical Sciences. 2(3), 1206-1209.

8. ICH, Q1A (R2) (2003). Stability Testing of New Drug Substances and Products, International Conference on Harmonization, Geneva, 1-17.

9. Singh. S., Bakshi. M. et al. (2000). Guidance on conduct of stress tests to determine inherent stability of drugs. Pharmaceutical Technology, 24: $1-14$.

10. Singh S, Singh B, Bahuguna R, Wadhwa L et al (2006). Stress degradation studies on ezetimibe and development of a validated stability-indicating HPLC assay. J Pharm Biomed Anal. 41(3), 10371040.

11. Singh. S., Bakshi. M. et al. (2004). ICH Guidance in Practice: Establishment of Inherent Stability of Secnidazole and Development of a validated Stability-Indicating High-Performance Liquid Chromatographic Assay Method, Journal of Pharmaceutical and Biomedical Analysis, 36(4), 769-775.

12. ICH, Q2 (R1) (2005). Validation of Analytical Procedures: Text and Methodology, International Conference on Harmonization, Geneva, 110 .

\section{Cite this article as:}

Singh Pradeep Kumar, Subas Chandra Dinda. Development and validation of a stability indicating RP-HPLC method for determination of eletriptan in eletriptan hydrobromide orally disintegrating tablets. Int. Res. J. Pharm. 2013; 4(6):179-182 